\title{
A Case of Restudy about the Visitor Management Issues of Stonehenge, UK
}

\begin{abstract}
Asst. Prof. Dr. Perihan Paksoy
Beykent University

Doi:10.5901/mjss.2014.v5n13p342

perihanpaksoy@beykent.edu.tr

Abstract

One of the UNESCO's World Heritage assets Stonehenge carries a vital importance as it's under the protection of this list and all land surrounding the monument is owned by conservation organizations. Stonehenge faced an issue of being referred to two different organizations with differing approaches to management as English Heritage owned the site itself and National Trust owned the surrounding download. Paksoy \& Colakoglu (2009) investigated in their study about the site Stonehenge and has advised suggestions about its major management problems of the site. Stonehenge with its major management problems is one of the evident examples where the conflicts of the stakeholders can be monitored in an apparent way. With the different issues and its problematic locations and 2 different management styles, the problems encountered here were inspected by the researches to find out if measures have been taken since then. As there are a great number of visitors preferring Stonehenge and this number is increasing each year, the management couldn't ignore to take urgent actions with the related problems. The researcher in this study analyzed whether their previous assumptions and propositions have been actualized in real measures.
\end{abstract}

Keywords: Heritage tourism, conservation in tourism, visitor management

\section{The Need to Embrace Living Communities in Site Management}

To be able to induce sustainable management and to improve sustainability in the long run especially in heritage sites become a crucial component as these sites need to be protected in all means. The associated managements could take any kind of measures but if the living communities are neglected, the all targeted and implemented policies and plans lose its importance.

It is essential that an integrated holistic approach to sustainable development and management that incorporates the views and involvement of principal stakeholders such as local residents be adopted (Nicholas, Tapa and Ko, 2009).The relationship between heritage and tourism is frequently characterized by contradictions and conflicts whereby conservationists perceive heritage tourism as compromising conservation goals for profit (Nuryanti 1996). In order to minimize these threats, there is a need for dialogue, cooperation, and collaboration among the various stakeholders involved.

As there is an always possibility that contradictions may occur in the conversation issues, the questioning of the residents beliefs and opinions about the related issue may help to reduce the tension and the stress that might be caused by the conflicts aroused and may bring out resolution with a negotiated result. If a common ground between the different interested parties can be found, then heritage tourism can be developed in a way that preserves the resources of the local community and is beneficial to all (Aas and Ladkin, 2005).

One of the core experiences of visiting a heritage space is of being there with others and bringing to the space knowledge of many other spaces. Personal experience is especially powerful (Smith, 2007: 135). In the light of the previous definition, it can be concluded that a host community consists of all those people in the host destination, whether they are homogenous or heterogeneous and regardless of whether the impacts of tourism are beneficial or otherwise (Alhasanat, 2010).

One of the great challenges in managing any cultural or natural asset is the need to mollify many stakeholders. On the surface, stakeholder consultation seems like rather straightforward process. There is often an assumption that the number of stakeholders is limited to traditional owners and user groups on the one hand and the tourism industry on the other. In reality, most assets have multiple stakeholders with differing degrees of connectivity to the asset, differing levels of legitimacy in being considered as a stakeholder (McKercher and Cros, 2002: 57).

\section{Deliberate View of Visitors}

If the visitors' views are comprehended and differentiated, the management could shape their managing style in accordance. Aimed at perceiving what the visitors think of the sites they have come to see, the information from the 
visitors need to be gathered and further analyzed by the site administrators.

According to Weaver (2011: 257) assessments of the extent to which this tourism heritage is developed as heritage tourism must consider its development and marketing as such, and also its actual interface with tourists. Gathering of information from the visitors could also be used for marketing purposes in understanding the visitor profile and enhancing the interaction between the visitors and the management of the site.

Poria, et al. (2005: 174) reported that individuals differ in their preferences towards the interpretation in relation to their perception and accordingly, managers of historic destinations are advised to identify tourists based on their perceptions and provide them with different angles of interpretation.

In contrast to differing perceptions of the visitors, the management could analyze whether the visitors have a mutual preference or an expectation from the site management or a mutual criticism that needs to be modified.

\section{Carrying Capacity and Access Management= Control of Tourists Flow}

The major impact of sites with high visitor numbers face with the matter of carrying capacity and its negative consequences if the problem cannot be handled quite properly. In sites where the visitors with a great sum end up with and especially at the same time such as in Stonehenge, the crowd management techniques are addressed as a solution.

This can only be accomplished through a multidisciplinary effort involving the different areas in which planners can contribute to understanding the synergetic dimension of economic positive externalities and the carrying capacity of vulnerable areas (Vaz et al, 2012: 289).

Understanding potential impacts of visitors on heritage assets is not easy. Impacts on host communities can be anticipated, such as when increased traffic, litter. Impacts of visitation on how tradition bearers and others use traditional knowledge, skills, and types of cultural expression can be more difficult to anticipate and plan to migrate (McKercher and Cros, 2002: 225). How difficult to project in advance every site management should be in alert of the possible impacts and take precautions to implemented and control accordingly for its efficiency.

\section{Stonehenge Main Problem Areas}

Stonehenge with its major management problems is one of the evident examples where the conflicts of the stakeholders can be monitored in an apparent way as with the different issues and its problematic locations and 2 different management style, the problems encountered here need to be answered and dealt in care (Paksoy \& Çolakoğlu, 2009: 223). The issues and the challenges faced at Stonehenge were studied by various researchers (Baxter \& Chippindale, 2005:139; Mason, 2006: 105; Young, Chadburn and Bedu, 2009: 76-79 quoted from Paksoy \& Çolakoğlu, 2009: 223)

One of the problems with Stonehenge was its location as it had been located in the triangle of land between the A303, A344 and Byway 12. Being in a conjunction there was traffic, car, parking and safety hazard problems. The second main problem was the management is bi-headed. The site land was managed by English Heritage, with staff based on site and at offices in Salisbury. Site management was shared by National Trust that owns 1500 acres surrounding the site. Moreover because of the high load of visitors and inefficient visitor centre there was a significant issue of capacity management and visitor centre lacking as well.

\section{Restudy of Stonehenge: What has been changed up to now?}

The first WHS Management Plan for Stonehenge was published in 2000. It outlined 24 objectives, including building a new world-class visitor centre, removing the roads from sight of Stonehenge, and increasing the extent of grassland to protect prehistoric monuments and their setting (Stonehenge World Heritage Team, 2009: 4).

In their previous study the researchers Paksoy and Çolakoğlu within the highlights of this WHS Management Plan 2009 and the commentary collected from the site http://www.stonehenge.co.uk/visitorscomments.php outlined five main suggestions for the major problem areas with their own solution projections which are listed as below:

Paksoy \& Çolakoğlu Suggestion in 2009 (p. 227):

I. Directions of highways have been changed but still there is a room for further improvement that could enlarge areas for visitors.

Situation Analysis in 2014:

A344 closed - the A344 was removed and grassed (Campbell-Dolloghan, 2013) - where it passes within yards of the stones (Kennedy, 2013; BBC, 2013). 
Paksoy \& Çolakoğlu Suggestion in 2009 (p. 227):

II. Most significant problems are due to visitor facilities, therefore their construction shouldn't be against according to the stones. Visitor centre should have been the starting point of tour. The paths built to reach here from the car park could be improved. There can be small trains used for transporting tourist with a longer route. As the tour will start in the visitor centre, visitors will be directed appropriately and the problem of overcrowd will be solved.

Situation Analysis in 2014:

In response to these negative impacts, the British Department of the Environment erected a perimeter fence in the spring of 1978 to protect the site. Though not allowed inside the fence, visitors to Stonehenge are permitted to wander freely outside the barrier for a close-up view of the stones (Timothy \& Boyd, 2003:126).

At the moment Stonehenge still continues to receive high amount of visitors, during the peak periods this could reach 2000 per hour. (See below table for total number of visitors to Stonehenge)

Table 1: Total Number of the Visits to Stonehenge

\begin{tabular}{|l|c|c|c|c|c|c|c|}
\hline & 2007 & 2008 & 2009 & 2010 & 2011 & 2012 & 2013 \\
\hline English Heritage (EH) \& ALVA & 869432 & 883603 & 990,705 & $1,009,973$ & $1,099,656$ & $1,043,756$ & $1,241,296$ \\
\hline \multicolumn{8}{|c|}{ Source: ALVA } \\
\hline
\end{tabular}

The percentage of visitors to Stonehenge has decreased by \%1 in 2007 compared to previous year; reversely in 2008 there has been an increase of $\% 2$ compared to 2007. In 2009 there was a rise of $\% 12$. In 2010 it only increased by $\% 2$. $\% 9$ growth had been recorded in 2011. Even in 2012 there was a drop of \%-5.10, by year 2013 Stonehenge had boomed its visitors by $\% 18.9$.

After the renovation Stonehenge has been reopened for service, however overcrowding and long queues still remain as a problem. According to Kennedy's study, Stonehenge's new visitor centre opened in December 2013 with $£ 27 \mathrm{~m}$ investment. This is a 'fit for purpose' building, located 1.5 miles $(2.4 \mathrm{~km})$ from the Stonehenge (Kennedy, 2013). The new visitor centre at Stonehenge has come in for heavy criticism from some tourists who are claiming that being at the centre - which opened last month - is chaotic because of long delays and severe overcrowding (ITV, 2014).Visitors to a new $£ 27$ million centre at Stonehenge have criticised English Heritage for presiding over "chaotic scenes" as the venue struggles to cope with the number of people it receives (Telegraph, 2014).

Some of the complaints about the new experience included reports of visitors queuing for more than an hour to board the 'land train' which carries people from the centre to the stones. The journey of a mile-and-a-half has taken just ten minutes.

Even the visitors complain about some of the certain issues there is also an improvement that needs to be highlighted. The management has put into service visitor shuttle. Visitor Shuttle service operates frequently from outside the shop and there is no need to pre-book. With this service it takes 10 minutes to reach the Stones. (English Heritage, 2014)

Paksoy \& Çolakoğlu Suggestion in 2009(p. 227):

III. Days of week can be separated for groups. For instance educational student groups may visit in certain days. Or the time of day can be allocated for certain groups.

Situation Analysis in 2014:

Pre-booking timed tickets is now essential for tourist groups. Advance booking is now required as entrance to Stonehenge is managed through timed tickets.

Paksoy \& Çolakoğlu Suggestion in 2009(p. 227):

IV. Both site and facilities need to be managed by one authority.

Situation Analysis in 2014:

Stonehenge is still managed by two authorities: English Heritage and National Trust. The historical part, café, the visitor centre and facilities like toilet is managed by English Heritage and the surrounding 827 hectares (2,100 acres) of downland by National Trust. (National Trust, 2014)

Paksoy \& Çolakoğlu Suggstion in 2009(p. 227):

V. Prices are acceptable and they are not high for a World Heritage Site. Therefore prices can be increased slightly to collect fund for a better service to visitors of Stonehenge.

Situation Analysis in 2014:

Entrance costs are still not too much high. There has been also a family discount as an additional price offer. For 
2014 entrance fee is designated as $£ 13.90$ for adults and $£ 8.30$ for children.

Introducing entrance fees to attractions may help counteract the threat of inadequate public funds for site maintenance and management (Reynisdottir et al., 2008: 1076). Furthermore if the prices can be slightly increased, there could be a resolution also for too much tourist flows as well. Making historical assets more exclusive (e.g., only so many visitors or tours per day by appointment only) or more expensive are two ways around the over-use (McKercher and Cros, 2002: 224). Stonehenge management prefers to apply lower price scale for now.

\section{Conclusion}

In regards of their previous study the researcher in this report have tried to put forward what measures have been taken in the problematic areas of a World Heritage Site in UK, Stonehenge. It has been observed that the challenging location of Stonehenge had been improved by closing one motorway that were creating both traffic and safety hazards. Even though a new modern visitor has been designed and opened up recently, the visitors still complain about the tourist overflow and overload. Management authority could not be united under one umbrella, though English Heritage managed area where tourists visit the most exceed National Trust. Therefore English Heritage seems to manage most of the touristic facilities. Small tourist's trains with a longer route may bring a more enjoyable travel which can include both the historical site of English Heritage and the natural land of National Trust surrounding the site as some of the tourists complain about the route's short period of time after a long wait in the queue. There is no major change in price scale and reservation for groups. However advance booking option has been vastly improved and visitors long queues seem to be minimized compared to past. It is essential for future research to make a comparison of the other English heritage sites and differentiate among them and in seeking differences and similarities.

\section{References}

Aas, C. And Adele Ladkin (2005). Stakeholder collaboration and heritage management. Annals of Tourism Research, 32(1), 28-48.

Alhasanat, S. (2010), Sociocultural Impacts of Tourism on the Local Community at Petra. European Journal of Scientific Research, 44(3), 374

ALVA Association of Leading Visitor Attractions (2009). http://www.alva.org.uk/visitor_statistics/ [Accessed 26.05.2014]

Baxter Ian, Chippindale Christopher (2005). Managing Stonehenge: The Tourism Impact and the Impact on Tourism. In: Sigala Marianna, Leslie David (Eds.), International Cultural Tourism: Management, Implications and Cases. London: Elsevier, pp. 138150.

BBC (2013). New £27m Stonehenge visitor centre to open. Available at: <http://www.bbc.com/news/uk-england-wiltshire-25402980> [Accessed 23 March 2014]

Campbell-Dolloghan, Kelsey (2013). Stonehenge's new visitor centre looks positively neolithic, 27 December 2013, Available at: http://gizmodo.com/stonehenges-new-visitor-center-looks-positively-neolit-1489129699 [Accessed 30 March 2014]

Darvill, T., \& Boyd, S. (2003). Heritage tourism. London: Prentice-Hall.

English-Heritage (2014). Facilities at Stonehenge, Available at: https://www.english-heritage.org.uk/daysout/properties/ Stonehenge /facilities?lang=en [Accessed 20 March 2014]

ITV (2014). http://www.itv.com/news/meridian/story/2014-01-14/new-stonehenge-visitor-centre-is-chaos/ [Accessed 06 May 2014]

Kennedy, Maev (2013). New Stonehenge visitor centre finally opens, The Guardian, 17 December 2013 Available at: http://www.theguardian.com/culture/2013/dec/17/stonehenge-visitor-centre-opens-english-heritage [Accessed 23 March 2014]

Mc Kercher Bob \& Du Cros Hilary (2002). Cultural Tourism, the Partnership between Tourism and Cultural Heritage Management. NY: The Haworth Hospitality Press.

Nicholas N. Lorraine, Brijech Tapa and Yong Jae Ko (2009). Residents' Perspectives of a World Heritage Site: The Pitons Management Area, St. Lucia. Annals of Tourism Research, 36(3), 390-412.

Nuryanti, W. (1996). Heritage and Postmodern Tourism. Annals of Tourism Research, 23(2), 249-260.

National Trust (2014). Facilities of Stonehenge, Available at: https://www.nationaltrust.org.uk/stonehenge-landscape/facilities-andaccess/ [Accessed on 15 March 2014]

Paksoy, P \& Çolakoğlu, N. (2009). A Case Study about the Visitor Management Conflict in Stonehenge, UK. ICSS Studies on Business Economics, Vol.1, 221-231.

Poria, Yaniv, Reichel Arie, Biran Avital (2005). Heritage Site Management Motivations and Expectations. Annals of Tourism Research, 33(1), pp. 162-178.

Reynisdottir, M., Song, H. and Agrusa, J. (2008). Willingness to pay entrance fees to natural attractions: An Icelandic case study, Tourism Management, 29(6), 1076-1083.

Smith, G., Jennifer, (2007). Learning from popular culture: Interpretation, visitors and critique. International Journal of Heritage Studies, 5, 135-148.

Stonehenge World Heritage Team (2009). Stonehenge World Heritage Site Management Plan Summary 2009. English Heritage: UK Telegraph, (2014). Stonehenge visitors attack 'chaos' at new £27m centre, Telegraph, 13 January 2014 Available at: <http://www. 
telegraph.co.uk/travel/travelnews/10568180/

Stonehenge -visitors-attack-chaos-at-new-27m-centre.html> [Accessed 28 March 2014]

Travelpulse (2013). Stonehenge to open new visitor centre in October, 17 September 2013, Available at: <http://www.travelpulse.com /news/destinations/stonehenge-to-open-new-visitor-center-in-october.html> [Accessed on 25 March 2014]

Weaver, David (2011). Contemporary Tourism Heritage as Heritage Tourism. Annals of Tourism Research, 38(1), $249-267$.

Vaz, E. Cabral,P., Caetanoa, M., Nijkampc, P., Painhoa, M. 2012. Urban heritage endangerment at the interface of future cities and past heritage: A spatial vulnerability assessment. Habitat International, 36, 287-294. 